УДК 338.4

О.С. Крайнова,

зав. кафедрой туризма

Филиала Московского университета им. С.Ю. Витте в г. Нижнем Новгороде, канд. экон. наук, дочент

\title{
ОБЕСПЕЧЕНИЕ БЕЗОПАСНОСТИ ТУРИСТОВ НА МАРШРУТЕ: СО- СТОЯНИЕ ПРОБЛЕМЫ И ПРАКТИЧЕСКОЕ ИССЛЕДОВАНИЕ НА МАТЕРИАЛАХ ТУРОПЕРАТОРА ВНУТРЕННЕГО ТУРИЗМА
}

\author{
O.S.Kraynova, \\ The Head of the Department of Tourism, \\ Branch of Moscow Witte University in Nizhny Novgorod, \\ candidate of economic science,associate professor \\ E-Mail: kraynovaos@mail.ru
}

\section{ENSURING THE SAFETY OF TOURISTS ON THE TRAVEL ROUTE: THE STATE OF THE PROBLEM AND PRACTICAL RESEARCH ON MATERIALS OF DOMESTIC TOURISM TOUR OPERATOR}

Аннотация.В статье предпринята попытка обоснования одного из направлений системного подхода к управлению безопасностью - формирование достаточного уровня информированности туристов о безопасности на маршруте путешествия. В качестве инструмента обоснования выступают результаты анкетирования клиентов нижегородского туроператора внутреннего туризма на предмет оценки туристами уровня безопасности автобусных туров, реализуемых компанией.

Ключевые слова: обеспечение безопасности, турист, маршрут путешествия, системный подход к управлению, маркетинговое исследование. 


\begin{abstract}
The article attempts to validate one of the fields of a systematic approach to safety management is the formation of sufficient awareness of the tourists about safety on the route of travel. As a tool of justification are the results of a questionnaire survey of the Nizhny Novgorod domestic tourism tour operator to assess the tourists ' level of safety of bus tours implemented by the company.
\end{abstract}

Keywords: security, tourist, travel route, system approach to management, marketing research.

К особенностям разработки инновационных решений по обеспечению безопасности в туризме относится тот факт, что приходится иметь дело с системой «человек - среда обитания», находящейся в динамическом режиме и предполагающей решение вопросов оперативной безопасности. Конечно, безопасность не является абсолютной, но ей можно управлять, что позволяет говорить о некотором допустимом уровне безопасности, при котором всегда существуют остаточный риск или опасность. Риск или опасность могут существенно вырасти в условиях существования неучтенных при формировании программы тура источников опасностей, проявления конкретного источника воздействия на опасном для туриста уровне, подверженности туриста воздействию определенных источников опасности.

Важным направлением системного подхода к управлению безопасностью в туризме считаются:

- стратегическое планирование турпродукта, основывающееся на составлении всеобъемлющих и «универсальных» положений по правилам и мерам безопасности туристов либо на том, что специалисты туроператора в соответствии с реализуемыми ими направлениями деятельности разрабатывают программы по обеспечению безопасности туров;

- учет человеческого фактора - важное стратегическое направление в обеспечении безопасности турпродукта, так как главная опасность таится в самом человеке: в его самоуверенности, переоценке своих сил и возможностей, 
пренебрежении к правилам безопасности, отсутствии элементарных знаний о выживании, а порой - в преступном легкомыслии;

- создание и внедрение автоматизированных систем стратегического анализа и контроля безопасности ресурсов туристического пакета.

В статье автор предпринимает попытку обоснования одного из направлений системного подхода к управлению безопасностью - формирование достаточного уровня информированности туристов о безопасности на маршруте путешествия и овладение необходимыми навыками в обеспечении собственной безопасности, поскольку не следует недооценивать повышение уровня грамотности и подготовленности туристов к самостоятельному (в первую очередь) принятию решений в условиях возникновения различного рода рисков. И в данном контексте, как представляется автору, необходимо первоначально определиться с вопросами восприятия туристом системы безопасности туристского путешествия, его отношением к уровню достаточности и гарантии выполнения обязательств со стороны туроператора.

С этой целью в рамках проводимого автором исследования было организовано анкетирование клиентов одного из нижегородских туроператоров, специализирующихся на организации внутреннего туризма, в основном, автобусных маршрутов по России.

Так, опрос в форме анкетирования предусматривал оценку туристами уровня безопасности автобусных туров, реализуемых компанией. В рамках исследования был изучен спрос на автобусные туры среди населения Нижегородской области и выявлены потребительские критерии безопасности туров, определено отношение туристов к безопасности автобусных туров на основе их знаний, оценена работа менеджеров по продажам туров в области безопасности.

План первичного маркетингового исследования, представленный в табл. 1, был разработан под клиентов конкретного туроператора, а сама процедура анкетирования проводилась в офисе по продажам турпродуктов.

Таблица 1 - План исследования безопасности туров туроператора внутреннего туризма (специализация - автобусные туры) 
[Составлено автором]

\begin{tabular}{|l|l|}
\hline Наименование раздела & \multicolumn{1}{|c|}{ Содержание раздела } \\
\hline 1.Разработка концепции исследования \\
\hline $\begin{array}{l}\text { 1.1 Определение целей } \\
\text { исследования }\end{array}$ & $\begin{array}{l}\text { Ссновной целью исследования является оценка тури- } \\
\text { стами уровня безопасности автобусных туров, реали- } \\
\text { зуемых туроператором. }\end{array}$ \\
\hline Для реализации исследовательского замысла необходи- \\
мо решить ряд задач:
\end{tabular}




\begin{tabular}{|c|c|}
\hline $\begin{array}{l}3.4 \text { Определение пе- } \\
\text { риодов, стоимости, } \\
\text { сроков, ответственных } \\
\text { за сбор информации }\end{array}$ & $\begin{array}{l}\text { Сроки: исследование проводилось с } 03.04 .2015 \text { г. по } \\
\text { 15.05.2015 г. } \\
\text { Период: высокий туристский сезон } \\
\text { Ответственный за сбор информации: Крайнова О.С. }\end{array}$ \\
\hline $\begin{array}{l}\text { 4. Методы обработки } \\
\text { u анализа полученной } \\
\text { информачии }\end{array}$ & $\begin{array}{l}\text { Метод обработки полученной информации: вручную } \\
\text { Методы анализа полученной информации: статистиче- } \\
\text { ские, методы группировки, сводки, установление взаи- } \\
\text { мосвязей } \\
\text { Характер представления результатов анализа: таблицы, } \\
\text { диаграммы }\end{array}$ \\
\hline $\begin{array}{l}\text { 5. Программные ре- } \\
\text { зультаты исследова- } \\
\text { ния }\end{array}$ & $\begin{array}{l}\text { Подтверждение/ опровержение рабочих гипотез } \\
\text { Разработка рекомендаций по повышению безопасности } \\
\text { туристов при совершении автобусных туров }\end{array}$ \\
\hline
\end{tabular}

Анализ полученных в ходе анкетирования данных демонстрировал следующее. В ходе исследования было опрошено 200 респондентов, из которых 96\% составляют женщины, 4\% - мужчины; подавляющее большинство респондентов являются квалифицированными специалистами с высшим образованием (69\%), 8\% - заместителями руководителя предприятия, $13 \%$ - руководителями службы, отдела, 4,5\% - студенты, 4,5 \% - служащие без высшего образования. $48 \%$ респондентов не состоят в браке, $52 \%$ респондентов не имеют детей. $88 \%$ имеют высшее образование, 4,5\% - незаконченное высшее образование, 7,5\% среднее образование. Именно эти категории граждан являются основными потребителями услуг туроператора.

Большинство опрошенных респондентов (78\%) совершает туристические поездки в пределах Российской Федерации 1 раз в год, 17,5\% - 2-3 раза в год и лишь 4,5\% - 4 и более раз в год, не совершающих поездки по Российской Федерации среди респондентов не оказалось (рис. 1). 


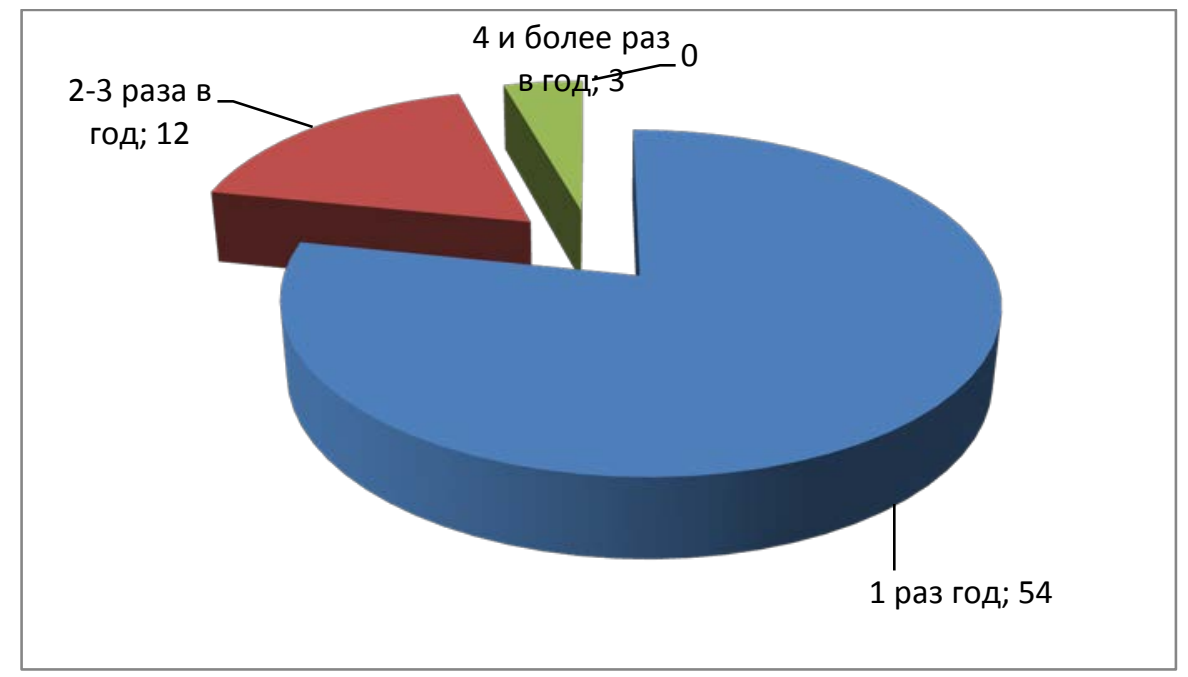

Рисунок 1 - Количество совершаемых поездок по РФ в год (раз)

[Составлено автором]

Предпочтения по видам отдыха туристов в Российской Федерации представлены на рисунке 2.

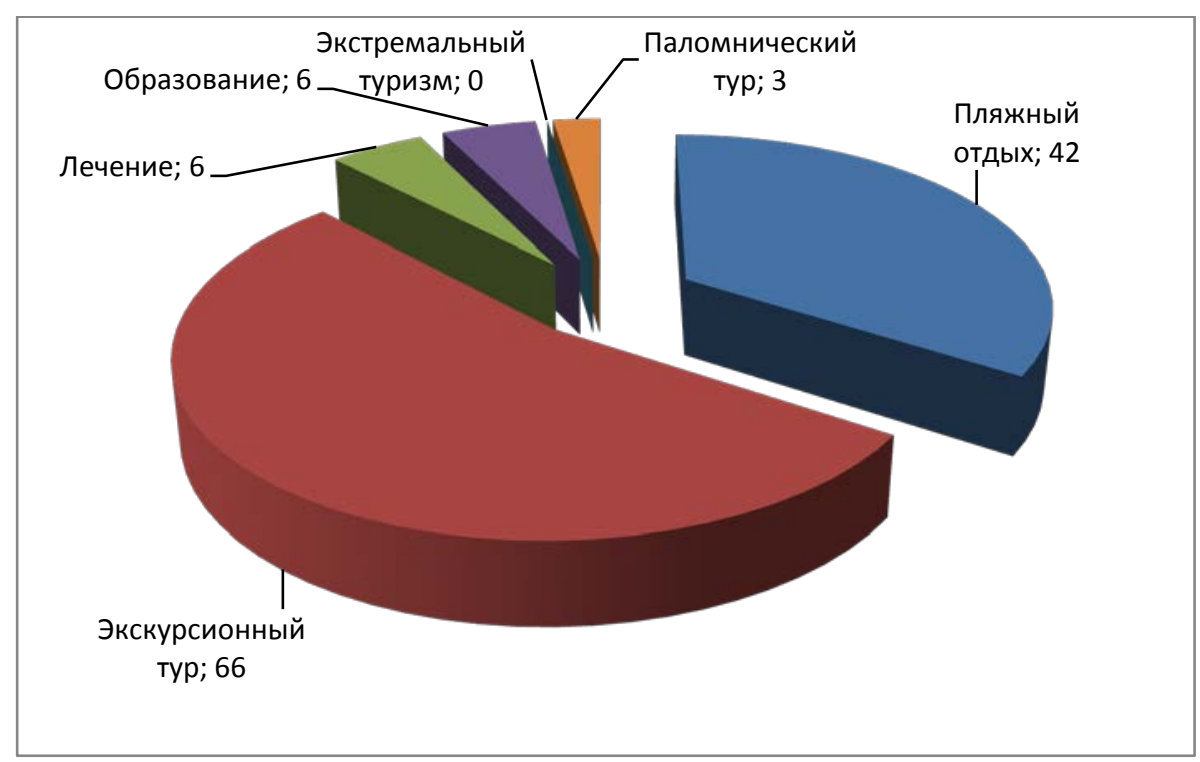

Рисунок 2 - Предпочтения по видам отдыха туристов в России

[Составлено автором]

Можно отметить, что наиболее популярными видами отдыха в Российской Федерации являются экскурсионный туризм и пляжный отдых - именно 
эти виды отдыха являются приоритетными направлениями в деятельности туроператора по России и СНГ.

Далее были выявлены предпочтения туристов в выборе средств передвижение при совершении тура (рис. 3).

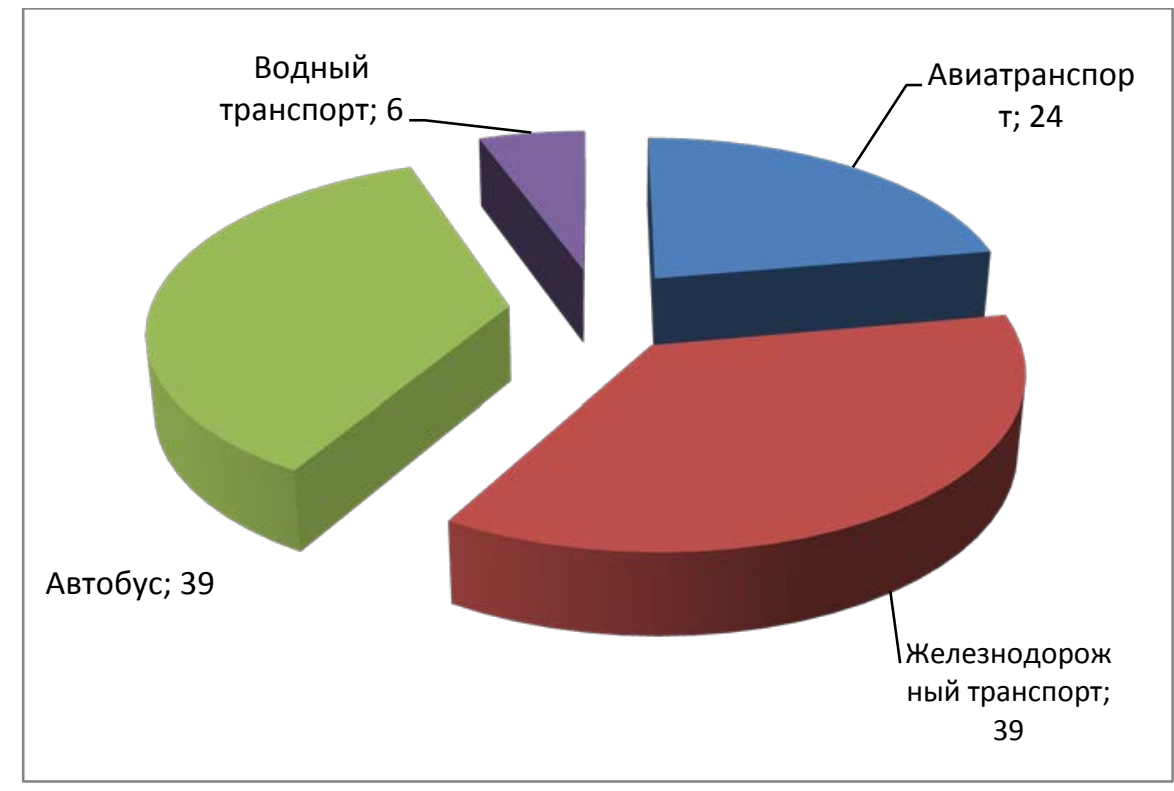

Рисунок 3 - Предпочтения респондентов по видам транспортных средств [Составлено автором]

Как видно из данных, представленных на рис. 3, самыми популярными видами транспорта являются железнодорожный транспорт и автобус - их отметили по 39 респондентов из общего числа опрошенных. Таким образом подтверждается тезис о том, что автобусные туры занимают лидирующие позиции по популярности среди населения. Это же подтверждает ответ на следующий вопрос анкеты, где подавляющее большинство респондентов - 66 человек, отмечают, что ранее они также совершали автобусные туры по России.

По мнению респондентов, самым привлекательным в автобусном туре является доступная цена и возможность за одну поездку познакомиться со многими достопримечательностями (рис. 4). 


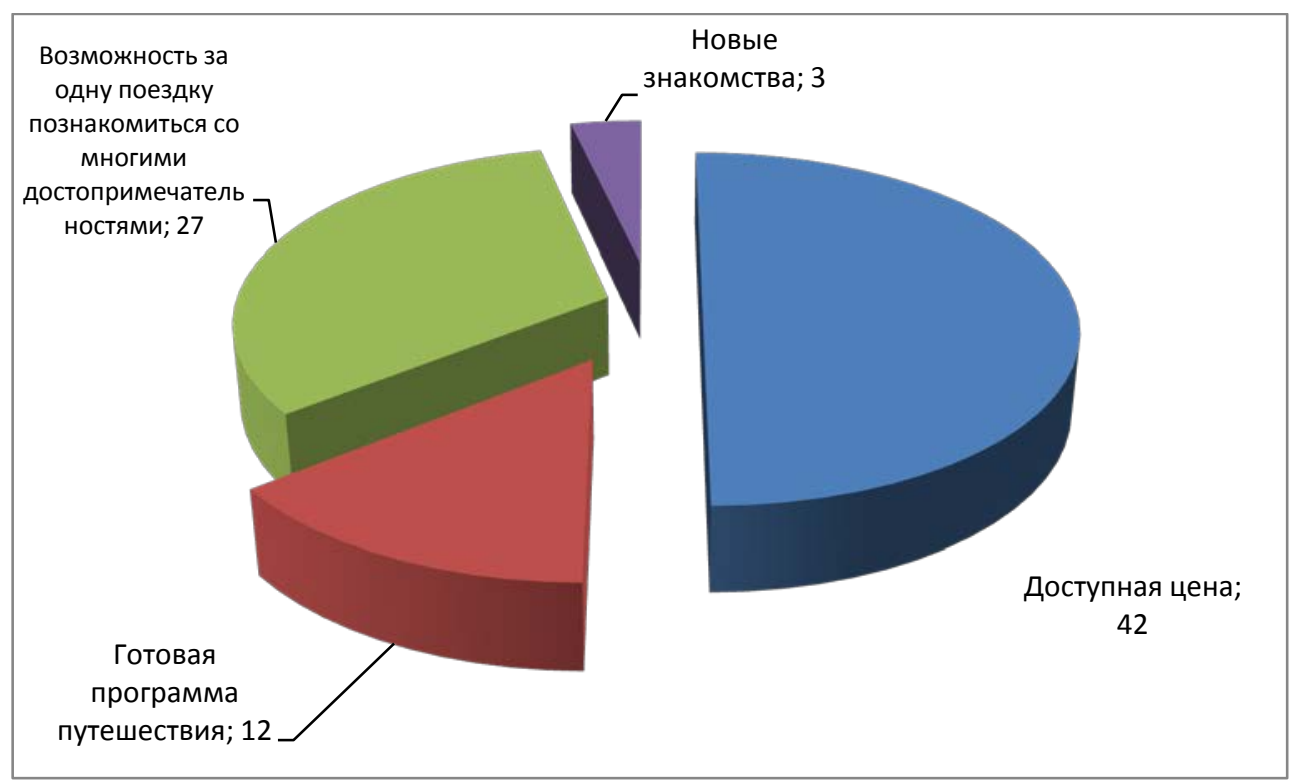

Рисунок 4 - Привлекательность автобусных туров

[Составлено автором]

Таким образом, можно сделать вывод, автобусные туры являются популярными среди населения благодаря относительной ценовой доступности в сочетании с большим количеством объектов показа, что в современной достаточно сложной геополитической и экономической обстановке зачастую является решающем в выборе вида тура и стратегия развития именно такого вида туризма туристической компанией в настоящее время является актуальной.

Прогнозируемый рост спроса на внутренний туризм, в том числе и на автобусные туры и высокая конкуренция на туристском рынке Российской Федерации заставляет туристические фирмы по-новому взглянуть на качество предоставляемых услуг, в том числе и в сфере безопасности туров. Автомобильный транспорт является самым аварийным, так в 2013 году произошло 204,1 тыс. автомобильных происшествий, для сравнения - на железнодорожном транспорте - 17 тыс., на внутреннем водном транспорте - 5 тыс., на воздушном - 30 тыс. происшествий. Такая статистика не может не волновать туристов, совершающих автобусные путешествия по России. Так о вопросах безопасности при совершении автобусных туров задумывалось подавляющее большинство респондентов - 91\%, поэтому вопрос о безопасности автобусных туров являет- 
ся очень актуальным. Ответственность за безопасность туров лежит на туроператоре, формирующем тур, но эта ответственность не должна сводиться только к исполнению законодательства Российской Федерации, но и должна быть одной из основополагающих при работе с клиентами.

Так, при проведении анкетирования 52\% респондентов ответили, что при покупке тура не были ознакомлены с правилами безопасности при совершении автобусных путешествий менеджером по продажам, а 74\% респондентов не получили «Памятку о правилах поведения в автобусном туре», только 56\% респондентов отметили, что были проинструктированы о правилах безопасности сопровождающим группы в салоне автобуса в начале путешествия! Причем элементарнейшие правила безопасности при совершении автобусных путешествий знают не все туристы (рис. 5).

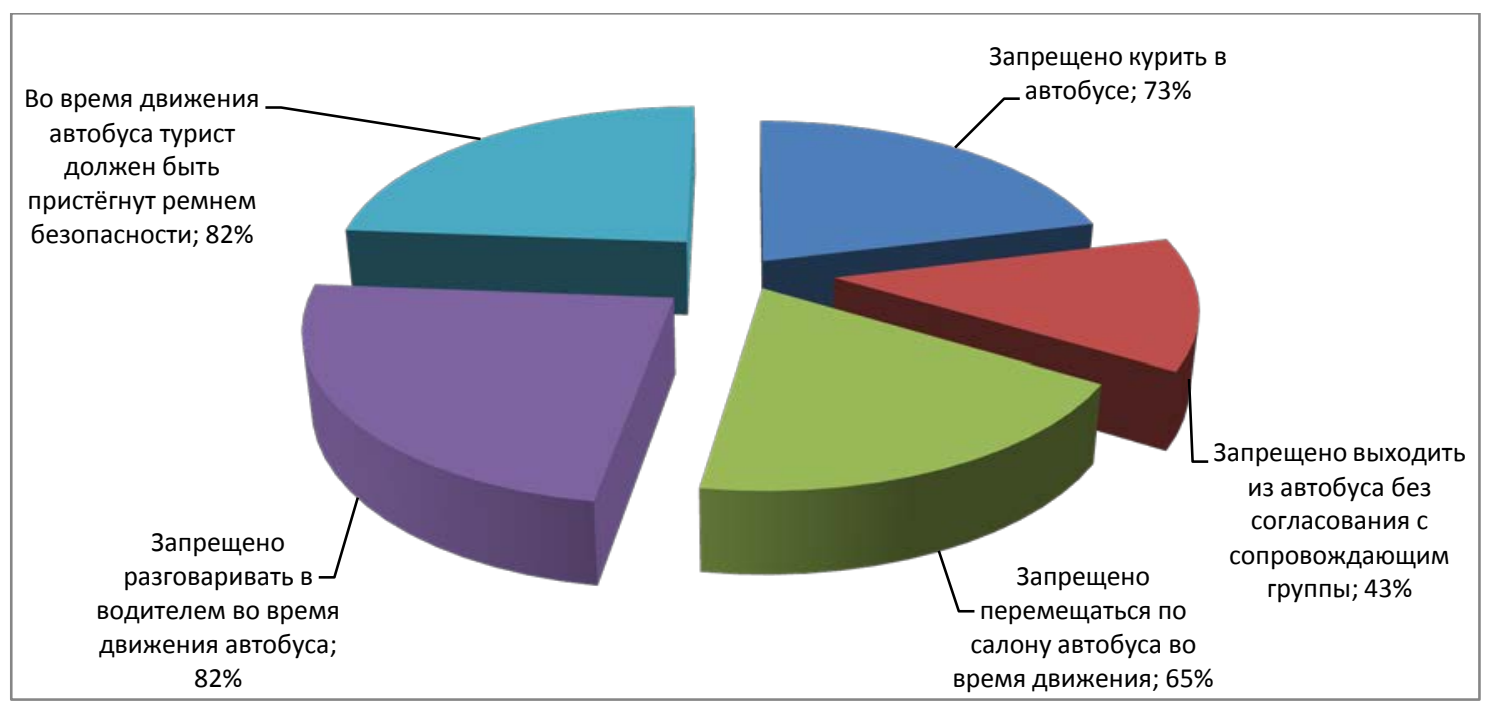

Рисунок 5 - Знание правил безопасности в автобусных турах

[Составлено автором]

Также имеют место вопросы по техническому состоянию туристических автобусов, комфортности путешествий и соответствию норм. В ходе опроса лишь 34\% респондентов отметили, что совершали путешествие на современном комфортабельном туристическом автобусе, только 35\% заявили о наличии системы поддержания микроклимата, 39\% респондентов имели в автобусе приборы для нагрева питьевой воды, по 22\% отметили не соответствие автобуса со- 
временным нормам, поломки и задержки в пути. Более подробно данные представлены на рисунке 6.

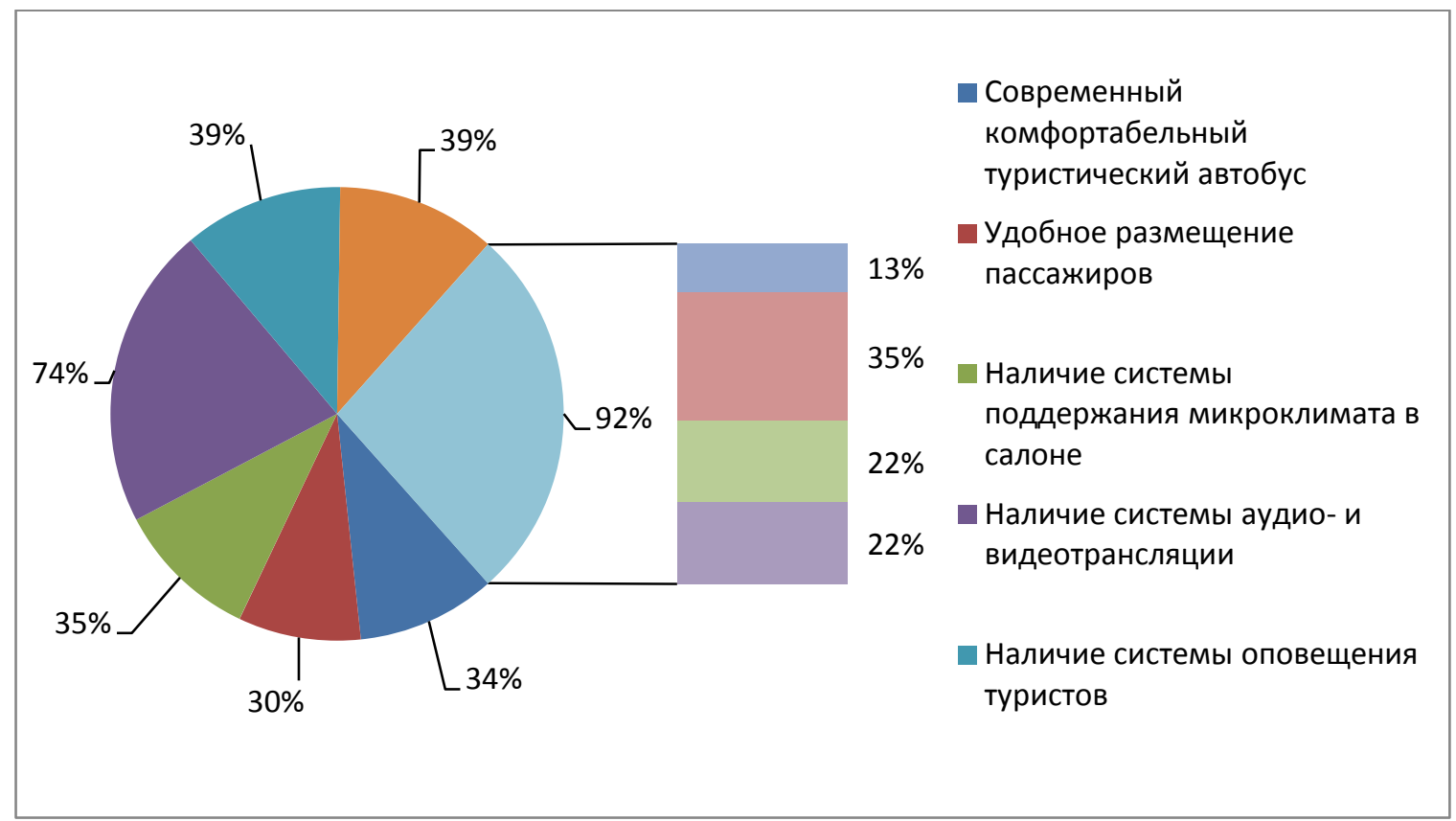

Рисунок 6 - Состояние автобусов туроператора (по мнению респондентов)

[Составлено автором]

Также в ходе анкетирования $82 \%$ респондентов отметили, что им не были предоставлены сведения о страховщике, экстренной помощи и компенсациях при возникновении несчастных случаев.

Все это говорит о недоработках в организации системы безопасности туров у конкретного туроператора и необходимости ее реформирования в части создания внутрифирменной стратегии безопасности с включением в нее всех сотрудников от менеджеров по продажам до гидов и водителей автобусов, а также активным вовлечение туристов на всех этапах оказания услуг от приобретения тура до окончания оказания услуги.

\section{Список литературы}

1. О безопасности: Федеральный закон от 28.12.2010 N 390-Ф3 / Правовой сервер "Консультант Плюс" / [Электронный ресурс] // URL: 
http://base.consultant.ru/cons/cgi/online.cgi?req=doc;base=LAW;n=108546 / (дата обращения: 15.04.2015)

2. Об основах туристской деятельности в Российской Федерации: Федеральный закон от 24.11.1996 № 132-Ф3 (ред. от 03.05.2012) / Правовой сервер "Консультант Плюс" / [Электронный ресурс] // URL: http://www.consultant.ru /document/cons_doc_LAW_129632/ (дата обращения: 12.02.2015)

3. Национальный стандарт Российской Федерации «Туристские услуги. Требования по обеспечению безопасности туристов ГОСТ Р 50644-2009: Приказ Федерального агентства по техническому регулированию и метрологии от 15.12.2009 № 773-ст / Правовой сервер "Консультант Плюс" / [Электронный реcypc] // URL: http://base.consultant.ru/cons/cgi/online.cgi? req=doc;base=EXP; $\mathrm{n}=481763$ ( (дата обращения: 12.03.2015)

4. Петров, С.В. Безопасный отдых и туризм [Текст]: Учебное пособие. / С. В. Петров, О. Л. Жигарев, О. Н. Токарева. - Новосибирск: АРТА, 2011. - 294 c.

5. Кулинкович М.А. Риск как мера опасности для жизни и здоровья человека в ходе туристско-экскурсионного обслуживания / М.А. Кулинкович. В сборнике: Индустрия туризма и сервиса: состояние, проблемы, эффективность, инновации. Нижний Новгород. 2015.

6. Григорьева М.В., Рябченко О.И., Эмиров И.Х. Инновационные стратегии обеспечения безопасности в туризме // TTПC. 2011. №15. URL: http://cyberleninka.ru/article/n/innovatsionnye-strategii-obespecheniya-bezopasnostiv-turizme (дата обращения: 28.06.2015).

7. Писаревский Е.Л. Актуальные проблемы обеспечения общественной безопасности в сфере туризма. // Интернет-журнал «Туризм: право и экономика», 2011. № 11. [Электронный ресурс] // URL статьи: http://www.centerbereg.ru/f762.html (дата обращения: 05.05.2015). 